\title{
Crack Extension Resistance of Normal-Strength Concrete Subjected to Elevated Temperatures
}

\author{
Jing Chen and Zhoudao Lu \\ College of Civil Engineering, Tongji University, Shanghai 200092, China \\ Correspondence should be addressed to Zhoudao Lu; lzd@tongji.edu.cn
}

Received 5 March 2014; Revised 29 May 2014; Accepted 30 May 2014; Published 26 June 2014

Academic Editor: Juan José del Coz Díaz

Copyright ( 92014 J. Chen and Z. Lu. This is an open access article distributed under the Creative Commons Attribution License, which permits unrestricted use, distribution, and reproduction in any medium, provided the original work is properly cited.

\begin{abstract}
Determination of the residual crack extension resistance curves $\left(K_{R}\right.$-curves) associated with cohesive force distribution on fictitious crack zone of complete fracture process is implemented in present research. The cohesive force distributes according to bilinear softening traction-separation law proposed by Petersson. Totally ten temperatures varying from $20^{\circ} \mathrm{C}$ to $600^{\circ} \mathrm{C}$ and the specimen size of $230 \times 200 \times 200 \mathrm{~mm}$ with initial-notch depth ratios 0.4 are considered. The load-crack mouth opening displacement curves $(P$-CMOD) of postfire specimens are obtained by wedge-splitting method from which the stress intensity factor curves $(K$-curves) are calculated. In each temperature, with the distribution of cohesive force along the fracture process zone, the residual fracture toughness $K_{R}(\Delta a)$ increases with increasing crack length $\Delta a$, whereas the $K_{R}$-curves decrease with increasing temperatures $T_{m}$ for the thermal damage induced. The stability analysis on crack propagation demonstrates that when the residual $K_{R}$-curve is higher than $K$-curve, the crack propagates steadily; otherwise, the crack propagates unsteadily.
\end{abstract}

\section{Introduction}

To describe the crack propagation in concrete structures, the crack extension resistance in terms of $K_{R}$ has been measured and the related characteristics were investigated by Hilsdorf and Brameshuber in 1984 [1], Mai in 1984 [2], and Karihaloo and Shah in 1987 [3] as well as Xu and Reinhardt in 1999 [4] which was calculated using the conventional approach proposed by Irwin et al. in the early 1960s. Xu and Reinhardt in 1998 [5] proposed an analytical method to determine the crack extension resistance $\left(K_{R^{-}}\right.$ curve) according to the cohesive force on the fictitious crack zone that is described directly by the softening tractionseparation law. The basic principle of the approach is that the crack extension resistance is composed of two parts. One part is the inherent toughness $K_{\mathrm{Ic}}^{\mathrm{ini}}$, which resists the initial propagation of an initial crack under loading. This means that a crack does not propagate when the stress intensity factor at the initial crack tip is less than the inherent toughness $K_{\mathrm{Ic}}^{\text {ini }}$. Another part is induced by the cohesive force distributed on the fictitious crack during crack propagation. Therefore, it is a function of the cohesive force distribution $f(\sigma)$, the tensile strength $f_{t}$ of the material, and the length of the propagating crack.

The main requirement for determining crack extension resistance curve based on cohesive force distribution during crack propagation is to know the load-crack mouth opening displacement $(P$-CMOD) curve a priori. Some characteristics of $K_{R}$-curve were investigated numerically on standard TPBT specimen for different concrete strength and specimen sizes [6]. It was observed that $K_{R}$-curve was dependent on compressive strength of concrete and had almost the same S-shape. It increased with increasing crack length and increasing strength of concrete. The obtained $K_{R}$-curves were almost independent of the specimen sizes. However, it was found that some difference could be noticed on the gained $K_{R}$-curve by using bilinear [7] and nonlinear [8] softening functions of concrete. The influence of specimen geometry (TPB and CT specimens) on the $K_{R}$-curves is considered by Kumar and Barai [9], and the influence of the specimen geometry on the $K_{R}$-curves was not observed for the specified specimen size and initial-crack length/depth ratio. 


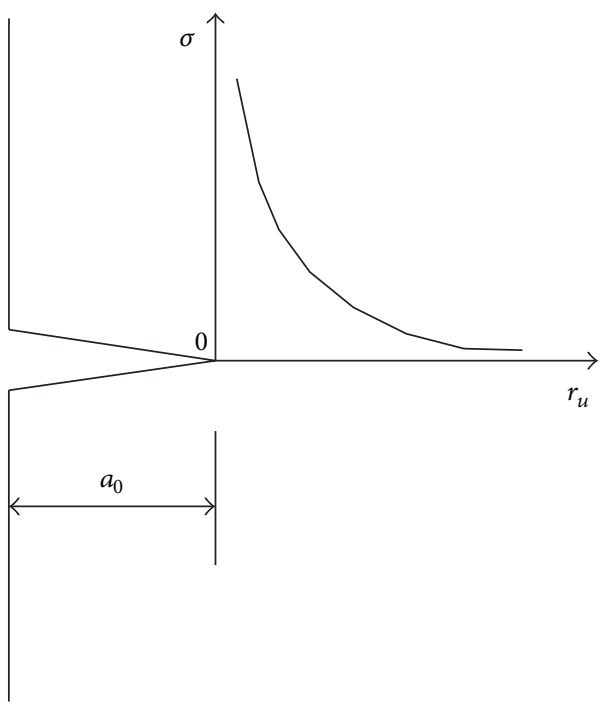

(a) Initial notch length

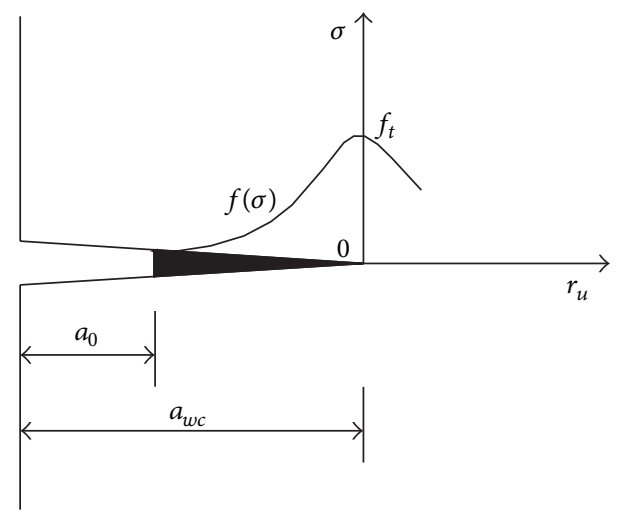

(c) Fully developed crack zone

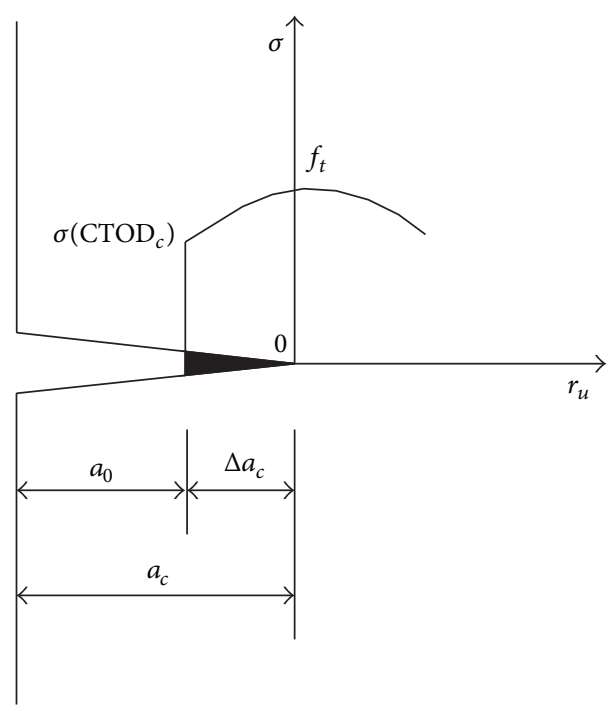

(b) Critical notch extension

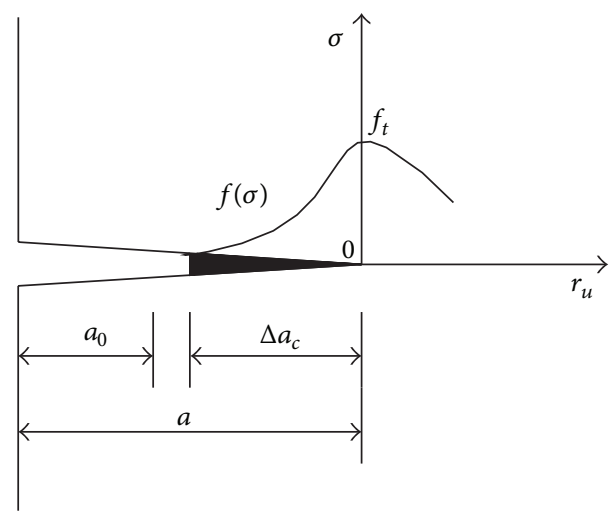

(d) Formation of new stress-free crack length

FIGURE 1: Four stages of crack propagation during the fracture process.

The influence of temperature on the fracture properties was considered by several researchers, mainly on the fracture energy and material brittleness [10-14], relative fewer discussions on the fracture toughness $[15,16]$, not mention the crack extension resistance of the complete fracture process. For the stability analyses of crack propagation, the comparison between $K_{R}$-curves and the corresponding stress intensity factor curves ( $K$-curves) can be taken as a crack propagation criterion to judge the stability of the crack in the loaded structures. This criterion could also be used in the analysis of the stability of structures that suffered high temperature or fire in a real situation.

The main objective of this research is to determine the residual crack extension resistance $\left(K_{R}\right.$-curve) of postfire concrete based on the cohesive force distributed on the fictitious crack zone, and the influence of temperatures on the $K_{R}$-curve is discussed. The wedge-splitting experiments of a total of ten temperatures varying from $20^{\circ} \mathrm{C}$ to $600^{\circ} \mathrm{C}$ and the specimens size $230 \times 200 \times 200 \mathrm{~mm}$ with initial-notch depth ratios of 0.4 are implemented.

\section{Determination of Residual $K_{R}$-Curve Based on Cohesive Stress Distribution}

2.1. Background. According to $K_{R}$-curve criterion [5], the crack extension resistance of a cracked solid consists of the inherent toughness $K_{\mathrm{Ic}}^{\mathrm{ini}}$ and the cohesive toughness $K_{c}(\Delta a)$ which increases with the increasing amount of crack extension. The cohesive toughness depends upon cohesive stress distribution $f(\sigma)$ which is a function of crack opening displacement $w$ and tensile strength of concrete $f_{t}$ and the propagating crack length $a$. At the onset of unstable crack propagation, the stress intensity factor $K$ at the tip of the propagating crack is expressed as

$$
K=K_{R}(\Delta a),
$$




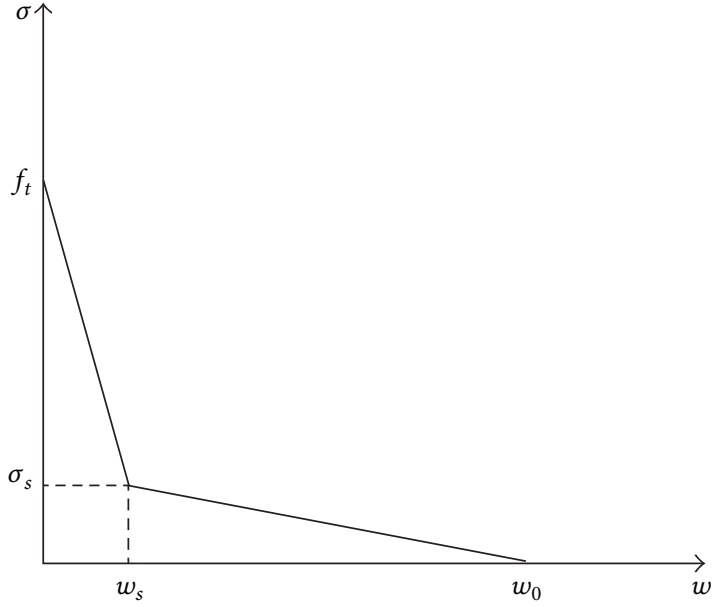

FIGURE 2: The bilinear softening traction-separation law.

where $K_{R}(\Delta a)$ is the crack extension resistance at crack extension length $\Delta a=a-a_{0}$. Also $K_{R}(\Delta a)$ is expressed in the following relation:

$$
\begin{gathered}
K_{R}(\Delta a)=K_{\mathrm{Ic}}^{\mathrm{ini}}+K_{c}(\Delta a), \\
K_{c}(\Delta a)=F_{1}\left(f_{t}, f(\sigma), \Delta a\right) .
\end{gathered}
$$

In order to develop the $K_{R}$-curve for complete fracture process considering the cohesive stress in fictitious fracture zone, the value of cohesive toughness $K_{c}$ at every stage of loading is important to determine. During crack propagation, four different stages are considered with the help of three characteristic crack lengths $\left(a_{0}, a_{c}\right.$, and $\left.a_{w c}\right)$ as represented in Figure 1 in which $r_{u}$ is the undamaged portion of the ligament, $a_{0}$ is initial crack length, $a_{c}$ is crack length at critical condition of unstable crack propagation, and $a_{w c}$ is the length of fully developed fictitious fracture zone after which the stress-free crack propagation will begin.

\subsection{Softening Traction-Separation Law of Postfire Concrete.} The softening traction-separation law is a priori to determine the $K_{R}$-curve, at room temperature, and many expressions have been proposed based on direct tensile test $[8,17-20]$. Based on numerical studies, simplified bilinear expressions for the softening traction-separation law (Figure 2 )were suggested by Petersson in 1981 [17], Hilsdorf and Brameshuber in 1991 [19], and Phillips and Zhang in 1993. The area under the softening curve was defined as the fracture energy $G_{F}$ by Hillerborg et al. in 1976 [21]. Therefore, one can get the following equation:

$$
G_{F}=\frac{1}{2}\left(f_{t} w_{s}+\sigma_{s} w_{0}\right)
$$

As a consequence, a general form of the simplified bilinear expression of the softening traction-separation law is given as follows:

$$
\sigma= \begin{cases}\frac{f_{t}-\left(f_{t}-\sigma_{s}\right) w}{w_{0}} & 0 \leq w \leq w_{s}, \\ \frac{\sigma_{s}\left(w_{0}-w\right)}{\left(w_{0}-w_{s}\right)} & w_{s} \leq w \leq w_{0}, \\ 0 & w \geq w_{0} .\end{cases}
$$

Different values of the break point $\left(\sigma_{s}, w_{s}\right)$ and the crack width $w_{0}$ at stress-free point were used for the expression proposed by different researchers. In present work, the bilinear softening function of concrete proposed by Petersson is used for postfire specimens as follows:

$$
\begin{aligned}
\sigma_{s} & =\frac{f_{t}}{3}, \\
w_{s} & =\frac{0.8 G_{F}}{f_{t}}, \\
w_{0} & =\frac{3.6 G_{F}}{f_{t}} .
\end{aligned}
$$

2.3. Analytical Method. The standard Green function [22] for the edge cracks with finite width of plate subjected to a pair of normal forces is used to evaluate the value of cohesive toughness. The general expression for the crack extension resistance for complete fracture associated with cohesive stress distribution in the fictitious fracture zone for Mode I fracture is given as follows:

$$
K_{R}(\Delta a)=K_{\mathrm{Ic}}^{\mathrm{ini}}+\int_{a_{0}}^{a} \frac{2 \sigma(x) F(x / a, a / h)}{\sqrt{\pi a}} d x,
$$

where

$$
\begin{aligned}
F\left(\frac{x}{a}, \frac{a}{h}\right)= & \frac{3.52(1-x / a)}{(1-a / h)^{3 / 2}}-\frac{4.35-5.28 x / a}{(1-a / h)} \\
& +\left\{\frac{1.30-0.30(x / a)^{3 / 2}}{\sqrt{1-(x / a)^{2}}}+0.83-1.76 \frac{x}{a}\right\} \\
& \times\left\{1-\left(1-\frac{x}{a}\right) \frac{a}{h}\right\} .
\end{aligned}
$$

Equation (7) is employed according to the conditions of four stages of crack propagation as mentioned below.

2.3.1. Case 1: When $a=a_{0}$. There is no advancement in the initial notch length at this stage of loading and the body remains in elastic condition, subjected to small load (up to $P_{\text {ini }}$ ) without any slow crack growth. Hence, cohesive stress $\sigma(x)=0$; the crack growth resistance remains equal to initiation toughness of the material. From (7), it is expressed as

$$
K_{R}=K_{\mathrm{Ic}}^{\mathrm{ini}} .
$$




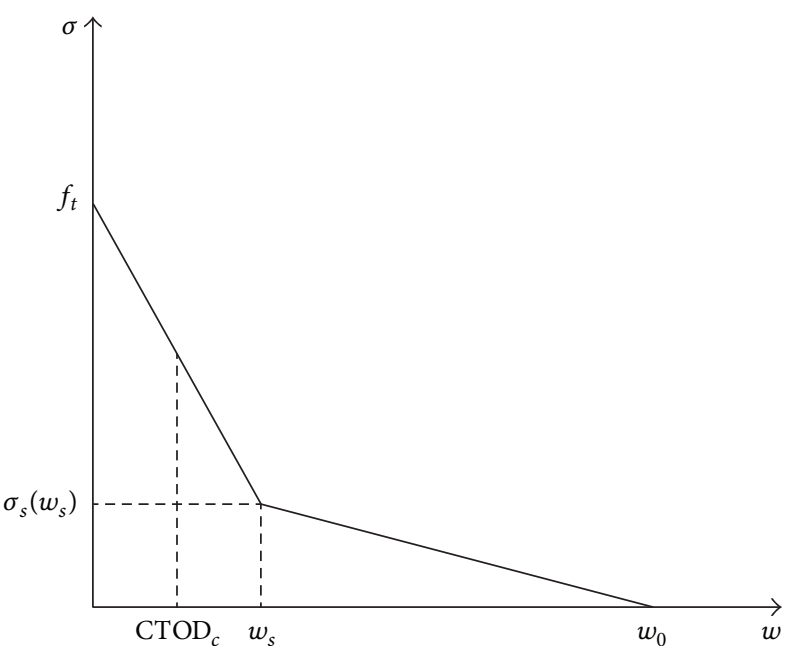

(a) When $\mathrm{CTOD}_{c} \leq w_{s}$

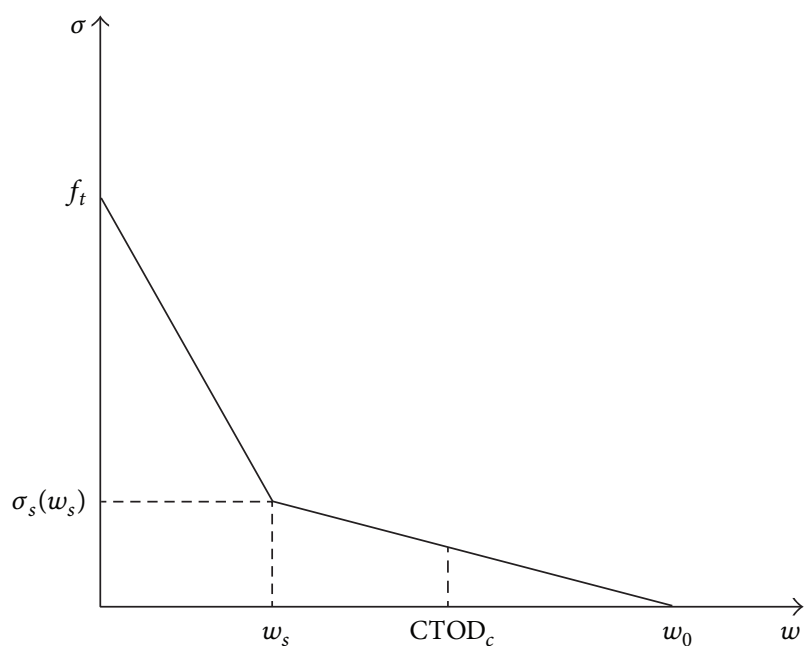

(b) When $\mathrm{CTOD}_{c}>w_{s}$

Figure 3: Two different situations for $\mathrm{CTOD}_{c}$ and $w_{s}$.

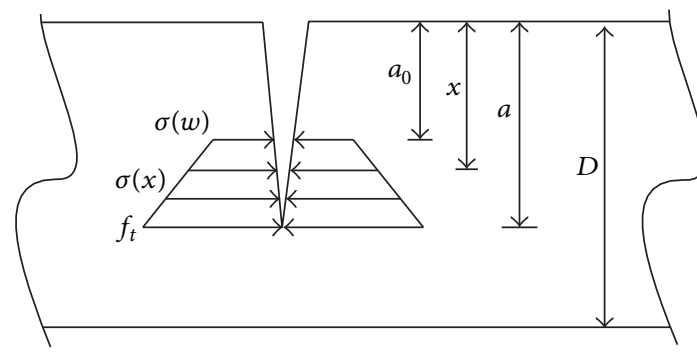

(a) The linear distribution of cohesive force

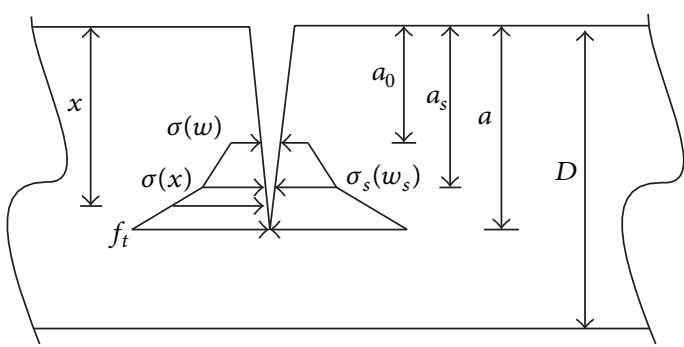

(b) The bilinear distribution of cohesive force

FIGURE 4: The cohesive distribution of crack propagation stage II.

2.3.2. Case 2: When $a_{0} \leq a \leq a_{c}$. The stable slow crack growth will take place until the effective crack extension $a_{c}$ corresponding to the maximum load $P_{u}$ is achieved. The cohesive force will start acting across the fictitious fracture zone resulting in the increase of crack extension resistance.

(a) For specimens subjected to temperatures less than $120^{\circ} \mathrm{C}$, the critical $\mathrm{CTOD}_{c}$ corresponding to maximum load $P_{u}$ is less than $w_{s}$, as shown in Figure 3(a). The distribution of cohesive stress along the fictitious fracture zone is approximated to be linear, as shown in Figure 4(a). The variation of cohesive stress along the fictitious fracture zone for this loading condition, that is, $a_{0} \leq a \leq a_{c}$ or $0 \leq \mathrm{CTOD} \leq \mathrm{CTOD}_{c}$, is written as

$$
\sigma(x)=\frac{\sigma(w)+\left(f_{t}-\sigma(w)\right)\left(x-a_{0}\right)}{\left(a-a_{0}\right)}
$$

where $\sigma(w)$ and $w$ are the values of cohesive stress and crack opening displacement, being at the tip of initialnotch, respectively. The value of $\sigma(w)$ is determined by using bilinear softening function as follows:

$$
\sigma(w)=\sigma_{s}\left(w_{s}\right)+\frac{w_{s}-w}{w_{s}}\left(f_{t}-\sigma_{s}\left(w_{s}\right)\right) .
$$

The crack extension resistance in this case is evaluated using (7) and (8).

(b) For specimens subjected to temperatures higher than $120^{\circ} \mathrm{C}$, the critical $\mathrm{CTOD}_{c}$ corresponding to maximum load $P_{u}$ is wider than $w_{s}$, as shown in Figure 3(b). The distribution of cohesive stress along the fictitious fracture zone is approximated to be bilinear, as shown in Figure 4(b). The variation of cohesive stress along the fictitious fracture zone for this loading condition, also, $a_{0} \leq a \leq a_{c}$ or $0 \leq \mathrm{CTOD} \leq \mathrm{CTOD}_{c}$, is written as

$$
\begin{aligned}
& \sigma_{1}(x)=\sigma(w)+\left(\sigma_{s}\left(w_{s}\right)-\sigma(w)\right) \frac{\left(x-a_{0}\right)}{\left(a_{s}-a_{0}\right)} \quad a_{s} \leq x \leq a_{0}, \\
& \sigma_{2}(x)=\sigma_{s}\left(w_{s}\right)+\left(f_{t}-\sigma_{s}\left(w_{s}\right)\right) \frac{\left(x-a_{s}\right)}{\left(a-a_{s}\right)} \quad a_{s} \leq x \leq a .
\end{aligned}
$$


The value of $\sigma(w)$ is determined by using bilinear softening function as follows:

$$
\sigma(w)=\frac{w_{0}-w}{w_{0}-w_{s}} \sigma_{s}\left(w_{s}\right)
$$

The limits of integration of (7) should be taken in two steps: $a_{0} \leq x \leq a_{s}$ for cohesive stress $\sigma_{1}(x)$ and $a_{s} \leq x \leq$ $a$ for cohesive stress $\sigma_{2}(x)$, respectively. The same Green's function $F(x / a, a / h)$ for a given effective crack extension will be determined using (8). The calculated formula is listed as follows:

$$
\begin{aligned}
K_{R}= & K_{\mathrm{Ic}}^{\mathrm{ini}}+\int_{a_{0}}^{a_{s}} \frac{2 \sigma_{2}(x) F(x / a, a / h)}{\sqrt{\pi a}} d x \\
& +\int_{a_{s}}^{a} \frac{2 \sigma_{3}(x) F(x / a, a / h)}{\sqrt{\pi a}} d x .
\end{aligned}
$$

The effective crack length at break point $a_{s}$ (as shown in Figure 4(b)) is computed from the following nonlinear expression [23] by substituting $\operatorname{COD}\left(a_{s}\right), \operatorname{CMOD}, a$, and $h$ :

$$
\begin{aligned}
\operatorname{COD}\left(a_{s}\right)=\operatorname{CMOD}\{ & \left(1-\frac{a_{s}}{a}\right)^{2} \\
& +\left(1.018-1.149 \frac{a}{h}\right) \\
& \left.\times\left[\frac{a_{s}}{a}-\left(\frac{a_{s}}{a}\right)^{2}\right]\right\}^{1 / 2},
\end{aligned}
$$

where $\operatorname{COD}\left(a_{s}\right)$ is the crack opening displacement at $a_{s}, a$ is the effective crack length (according to (18)), and $h$ is the specimen height.

2.3.3. Case 3: When $a_{c} \leq a \leq a_{w 0}$. During this stage of the applied load for all temperatures, corresponding CTOD and effective crack length have increased more than maximum load $P_{u}, \mathrm{CTOD}_{c}$, and critical effective crack extension $a_{c}$, respectively. The cohesive stress distribution for this case will take a bilinear shape, as shown in Figure 4(b). It is the same situation as case 2 part (b), and the crack extension resistance $K_{R}$ at this stage would be calculated according to (14). This case is shown in Figure 5.

2.3.4. Case 4: When $a \geq a_{w 0}$. This situation of loading corresponds to the descending portion of $P$-CMOD curve. At the effective crack extension, $a_{w 0}$, full shape of cohesive stress distribution is allowed to develop, and beyond further extension in crack during loading, a new stress-free crack in front of the initial notch tip will form. This case is shown

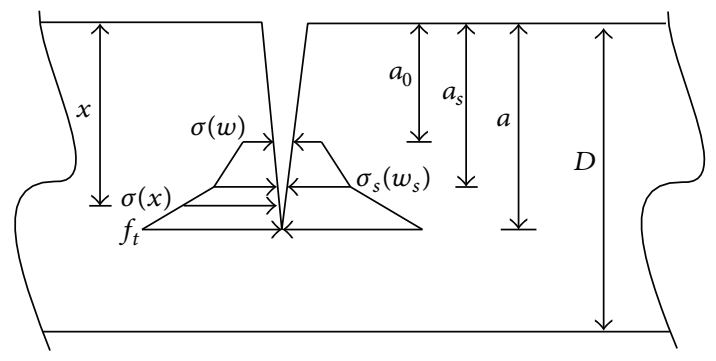

FIGURE 5: Crack propagation stage III.

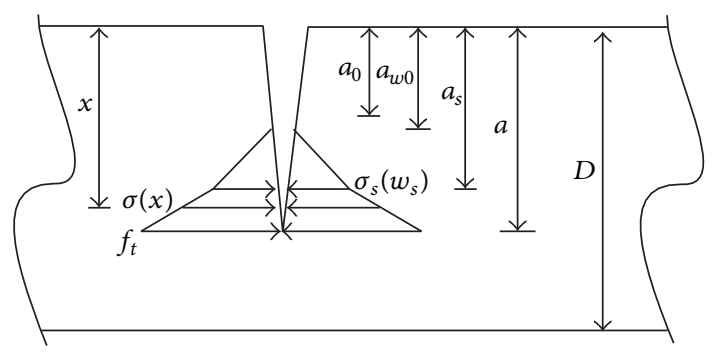

FIGURE 6: Crack propagation stage IV.

in Figure 6 and the stress distribution is expressed with the following relation:

$$
\begin{aligned}
& \sigma_{1}(x)=0 \quad a_{0} \leq x \leq a_{w 0}, \\
& \sigma_{2}(x)=\sigma_{s}\left(w_{s}\right) \frac{\left(x-a_{w 0}\right)}{\left(a_{s}-a_{w 0}\right)} \quad a_{s} \leq x \leq a_{w 0}, \\
& \sigma_{3}(x)=\sigma_{s}\left(w_{s}\right)+\left(f_{t}-\sigma_{s}\left(w_{s}\right)\right) \frac{\left(x-a_{s}\right)}{\left(a-a_{s}\right)} \quad a_{s} \leq x \leq a .
\end{aligned}
$$

Similar to (15), the effective crack length $a_{w 0}$ corresponding to zero stress of new fictitious fracture zone as shown in Figure 6 is computed from the following nonlinear expression:

$$
\begin{aligned}
\operatorname{COD}\left(a_{w 0}\right)=\operatorname{CMOD}\{ & \left(1-\frac{a_{w 0}}{a}\right)^{2} \\
& +\left(1.018-1.149 \frac{a}{h}\right) \\
& \left.\times\left[\frac{a_{w 0}}{a}-\left(\frac{a_{w 0}}{a}\right)^{2}\right]\right\}^{1 / 2},
\end{aligned}
$$




$$
\begin{aligned}
\operatorname{COD}\left(a_{s}\right)=\operatorname{CMOD}\{ & \left(1-\frac{a_{s}}{a}\right)^{2} \\
+ & \left(1.018-1.149 \frac{a}{h}\right) \\
& \left.\times\left[\frac{a_{s}}{a}-\left(\frac{a_{s}}{a}\right)^{2}\right]\right\}^{1 / 2} .
\end{aligned}
$$

The evaluation of crack extension resistance in this case is also done using (7) and (8).

\subsection{Determination of Equivalent Crack Extension}

2.4.1. Assumption. Linear asymptotic superposition assumption $[5,6]$ is considered to introduce the nonlinearity effect in $P$-CMOD curves during loading of concrete test specimens. This assumption enables us to introduce linear elastic fracture mechanics (LEFM) for calculating fracture parameters during every stage of loading in concrete structures. The hypotheses of the assumption are given as follows.

(1) The nonlinear characteristic of the P-CMOD curve is caused by fictitious crack extension in front of a stressfree crack.

(2) An effective crack consists of an equivalent-elastic stress-free crack and equivalent-elastic fictitious crack extension.

2.4.2. Equivalent Crack Extension for WS Specimen. The equivalent-elastic crack length for WS specimen is expressed as [24]

$$
a=\left(h+h_{0}\right)\left\{1-\left(\frac{13.18}{\mathrm{CMODE} t / P+9.16}\right)^{1 / 2}\right\}-h_{0} .
$$

The empirical expression (18) is valid within $2 \%$ accuracy for $0.2 \leq \alpha \leq 0.8$. The residual Young's modulus $E$ is calculated using the $P$-CMOD curve as

$$
E=\frac{1}{t c_{i}}\left[13.18 \times\left(1-\frac{a_{0}+h_{0}}{h+h_{0}}\right)^{2}-9.16\right],
$$

where $c_{i}=\mathrm{CMOD} / P$, the segment compliance; $t$ is the specimens thickness; $h$ is the specimens height; and $h_{0}$ is the thickness of clip gauge holder. The value of equivalent-elastic crack length $a$ and residual $E$ is listed in Table 1.

2.4.3. Calculation of Crack Opening Displacement. The crack opening displacement at position $x$ along the fictitious crack line $\operatorname{COD}(x)$ is computed from the known value of CMOD using the following expression [23]:

$$
\begin{aligned}
\operatorname{COD}(x)=\operatorname{CMOD} & \left\{\left(1-\frac{x}{a}\right)^{2}\right. \\
& \left.+\left(1.018-1.149 \frac{a}{h}\right)\left[\frac{x}{a}-\left(\frac{x}{a}\right)^{2}\right]\right\}^{1 / 2} .
\end{aligned}
$$

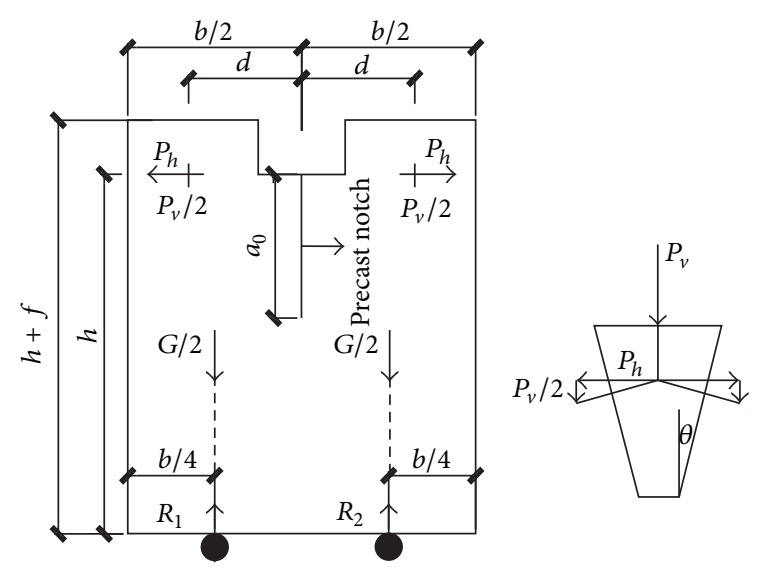

Figure 7: Geometry of specimens.

Also, the value of cohesive stress along the fictitious fracture zone corresponding to crack opening displacement at all stages of loading is evaluated using bilinear stressdisplacement softening law as given in (3).

2.5. Calculation of Double-K Fracture Parameters. The parameters like initiation toughness $K_{\mathrm{Ic}}^{\mathrm{ini}}$ and stress intensity factors (SIF) are required to be calculated to judge the stability of a propagating crack in a loaded structure using $K_{R}(\Delta a)$ curve analysis. The LEFM formula for the corresponding test specimen geometries is used for this purpose.

The SIF for WS test specimens is written as [24]

$$
\begin{aligned}
K(P, a) & =\frac{P \times 10^{-3}}{t h^{1 / 2}} f(\alpha), \\
f(\alpha) & =\frac{3.675 \times[1-0.12(\alpha-0.45)]}{(1-\alpha)^{3 / 2}}, \quad \alpha=\frac{a}{h} .
\end{aligned}
$$

The empirical expression (21) is valid within $2 \%$ accuracy for $0.2 \leq \alpha \leq 0.8$.

\section{Experimental Research}

3.1. Experimental Program and Experimental Phenomena. To obtain the complete $P$-CMOD curves, the wedge-splitting tests were implemented. A total of 50 concrete specimens with the same dimensions $230 \times 200 \times 200 \mathrm{~mm}$ were prepared, the geometry of the specimens is shown in Figure $7(b=200 \mathrm{~mm}, d=65 \mathrm{~mm}, h=200 \mathrm{~mm}, f=$ $30 \mathrm{~mm}, a_{0}=80 \mathrm{~mm}$, and $\theta=15^{\circ}$ ). The concrete mix ratios (by weight) were Cement: Sand: Coarse aggregate $:$ Water $=$ $1.00: 3.44: 4.39: 0.80$, with common Portland cement-mixed medium sand and $16 \mathrm{~mm}$ graded coarse aggregate. All the specimens had a precast notch of $80 \mathrm{~mm}$ height and $3 \mathrm{~mm}$ thickness, achieved by placing a piece of steel plate into the molds prior to casting. Each wedge splitting specimen was embedded with a thermal couple in the center of the specimens for temperature control.

Nine heating temperatures, ranging from $65^{\circ} \mathrm{C}$ to $600^{\circ} \mathrm{C}$ $\left(T_{m}=65^{\circ} \mathrm{C}, 120^{\circ} \mathrm{C}, 200^{\circ} \mathrm{C}, 300^{\circ} \mathrm{C}, 350^{\circ} \mathrm{C}, 400^{\circ} \mathrm{C}, 450^{\circ} \mathrm{C}\right.$, 
TABLE 1: Experimental results of fracture parameters.

\begin{tabular}{|c|c|c|c|c|c|c|c|c|c|c|c|}
\hline Specimen & Temperature & $\begin{array}{l}P_{\text {ini }} \\
(\mathrm{kN})\end{array}$ & $\begin{array}{l}\mathrm{CMOD}_{\text {ini }} \\
(\mathrm{mm})\end{array}$ & $\begin{array}{c}P_{u} \\
(\mathrm{kN})\end{array}$ & $\begin{array}{c}\mathrm{CMOD}_{c} \\
(\mathrm{~mm})\end{array}$ & $\begin{array}{c}\mathrm{CTOD}_{c} \\
(\mathrm{~mm})\end{array}$ & $\begin{array}{c}E \\
(\mathrm{GPa}) \\
\end{array}$ & $\begin{array}{l}a_{c} \\
(\mathrm{~h})\end{array}$ & $\begin{array}{c}K_{\mathrm{Ic}}^{\mathrm{ini}} \\
\left(\mathrm{MPa} \cdot \mathrm{m}^{1 / 2}\right)\end{array}$ & $\begin{array}{c}K_{\mathrm{Ic}}^{\mathrm{un}} \\
\left(\mathrm{MPa} \cdot \mathrm{m}^{1 / 2}\right)\end{array}$ & $\begin{array}{c}G_{F} \\
(\mathrm{~N} / \mathrm{m})\end{array}$ \\
\hline WS1 & & 6.19 & 0.068 & 8.33 & 0.174 & 0.065 & 15.30 & 0.53 & 0.505 & 1.061 & 234.15 \\
\hline WS2 & & 6.28 & 0.047 & 9.81 & 0.120 & 0.039 & 20.51 & 0.48 & 0.523 & 1.070 & 483.66 \\
\hline WS3 & $20^{\circ} \mathrm{C}$ & 7.26 & 0.063 & 10.40 & 0.210 & 0.079 & 20.66 & 0.57 & 0.610 & 1.497 & 438.22 \\
\hline WS4 & & 7.02 & 0.086 & 7.92 & 0.152 & 0.060 & 18.88 & 0.56 & 0.357 & 1.091 & 219.39 \\
\hline WS5 & & 5.65 & 0.060 & 9.39 & 0.237 & 0.096 & 15.45 & 0.54 & 0.503 & 1.213 & 321.05 \\
\hline Average & & 6.55 & 0.065 & 9.17 & 0.178 & 0.068 & 18.16 & 0.54 & 0.498 & 1.186 & 339.30 \\
\hline WS6 & & 6.98 & 0.055 & 11.31 & 0.195 & 0.078 & 21.73 & 0.56 & 0.550 & 1.594 & 425.91 \\
\hline WS7 & & 3.88 & 0.050 & 8.23 & 0.163 & 0.100 & 24.79 & 0.66 & 0.303 & 1.664 & 482.62 \\
\hline WS8 & $65^{\circ} \mathrm{C}$ & 6.88 & 0.078 & 10.41 & 0.212 & 0.087 & 19.43 & 0.57 & 0.557 & 1.518 & 487.75 \\
\hline WS9 & & 7.94 & 0.052 & 10.71 & 0.164 & 0.087 & 23.25 & 0.60 & 0.511 & 1.685 & 480.51 \\
\hline WS10 & & 6.32 & 0.056 & 11.67 & 0.229 & 0.086 & 16.60 & 0.54 & 0.562 & 1.507 & 522.36 \\
\hline Average & & 6.42 & 0.058 & 10.47 & 0.193 & 0.088 & 21.16 & 0.59 & 0.480 & 1.594 & 479.83 \\
\hline WS11 & & 5.03 & 0.064 & 8.37 & 0.191 & 0.056 & 10.65 & 0.47 & 0.518 & 0.900 & 396.52 \\
\hline WS13 & & 4.69 & 0.093 & 8.25 & 0.224 & 0.084 & 11.87 & 0.53 & 0.417 & 1.058 & 517.82 \\
\hline WS12 & $120^{\circ} \mathrm{C}$ & 4.71 & 0.070 & 7.53 & 0.357 & 0.152 & 9.48 & 0.60 & 0.419 & 1.202 & 654.73 \\
\hline WS14 & & 2.79 & 0.030 & 7.53 & 0.198 & 0.083 & 15.42 & 0.58 & 0.249 & 1.107 & 345.46 \\
\hline WS15 & & - & - & - & - & - & - & - & - & - & - \\
\hline Average & & 4.31 & 0.064 & 7.92 & 0.243 & 0.094 & 11.86 & 0.55 & 0.401 & 1.067 & 478.63 \\
\hline WS21 & & 1.89 & 0.182 & 3.40 & 0.653 & 0.283 & 2.45 & 0.61 & 0.168 & 0.556 & 437.92 \\
\hline WS22 & & 3.48 & 0.185 & 5.53 & 0.667 & 0.280 & 3.49 & 0.59 & 0.309 & 0.841 & 611.47 \\
\hline WS23 & $300^{\circ} \mathrm{C}$ & 1.82 & 0.121 & 3.38 & 0.672 & 0.271 & 1.91 & 0.57 & 0.162 & 0.480 & 341.77 \\
\hline WS24 & & 2.61 & 0.194 & 4.97 & 0.577 & 0.262 & 1.99 & 0.52 & 0.232 & 0.589 & 564.12 \\
\hline WS25 & & 2.03 & 0.096 & 4.17 & 0.651 & 0.361 & 4.03 & 0.68 & 0.175 & 0.913 & 549.99 \\
\hline Average & & 2.37 & 0.156 & 4.29 & 0.644 & 0.291 & 2.78 & 0.59 & 0.209 & 0.676 & 501.05 \\
\hline WS36 & & 1.52 & 0.126 & 3.37 & 1.009 & 0.544 & 1.41 & 0.62 & 0.135 & 0.582 & 611.53 \\
\hline WS37 & & - & - & - & - & - & - & - & - & - & - \\
\hline WS38 & $450^{\circ} \mathrm{C}$ & 1.52 & 0.163 & 3.26 & 1.419 & 0.660 & 1.46 & 0.62 & 0.135 & 0.527 & 482.45 \\
\hline WS39 & & 1.12 & 0.296 & 3.07 & 1.348 & 0.617 & 1.34 & 0.64 & 0.100 & 0.563 & 663.10 \\
\hline WS40 & & 0.99 & 0.105 & 2.94 & 1.394 & 0.666 & 1.58 & 0.68 & 0.088 & 0.659 & 678.79 \\
\hline Average & & 1.29 & 0.172 & 3.16 & 1.293 & 0.622 & 1.48 & 0.64 & 0.115 & 0.583 & 608.97 \\
\hline WS46 & & 0.76 & 0.443 & 1.13 & 1.482 & 0.684 & 0.47 & 0.65 & 0.067 & 0.221 & 228.23 \\
\hline WS47 & & 0.53 & 0.139 & 1.48 & 2.082 & 0.684 & 0.48 & 0.64 & 0.063 & 0.277 & 395.06 \\
\hline WS48 & $600^{\circ} \mathrm{C}$ & 0.81 & 0.324 & 1.65 & 1.908 & 0.813 & 1.14 & 0.76 & 0.072 & 0.550 & 539.22 \\
\hline WS49 & & 0.58 & 0.436 & 1.14 & 1.687 & 0.973 & 0.38 & 0.65 & 0.052 & 0.225 & 331.99 \\
\hline WS50 & & 0.62 & 0.279 & 1.48 & 2.082 & 0.727 & 0.38 & 0.62 & 0.068 & 0.213 & 273.07 \\
\hline Average & & 0.62 & 0.324 & 1.38 & 1.848 & 0.799 & 0.57 & 0.67 & 0.064 & 0.297 & 353.51 \\
\hline
\end{tabular}


$500^{\circ} \mathrm{C}$, and $600^{\circ} \mathrm{C}$ ), were adopted with the ambient temperature as a reference. Because it was recognized that the fracture behavior measurements were generally associated with significant scatter, five repetitions were performed for each temperature. An electric furnace with net dimensions $300 \times 300 \times 900 \mathrm{~mm}$ was used for heating. When the designated $T_{m}$ was reached, the furnace was shut down, and the specimens were naturally cooled for 7 days prior to the test.

A closed-loop servocontrolled hydraulic jack with a maximum capacity of $1000 \mathrm{kN}$ was employed to conduct the wedge splitting test. Two clip-on extensometers were suited at the mouth and the tip of the crack to measure the crack mouth opening displacement (CMOD) and crack tip opening displacement (CTOD). To obtain the complete $P$-CMOD curves (as shown in Figure 8), the test rate was fixed at $0.4 \mathrm{~mm} / \mathrm{min}$, such that it took approximately 20 minutes to complete a single test of specimens subjected to less than $300^{\circ} \mathrm{C}$ and 30 minutes for beyond $300^{\circ} \mathrm{C}$.

3.2. Experimental Results and Discussion. The recorded maximum load $P_{u}$, the recorded crack mouth opening displacement $\mathrm{CMOD}_{c}$ at $P_{u}$, the calculated crack tip opening displacement CTOD based on (20), the initial cracking load $P_{\text {ini }}$ determined by graphical method, the calculated residual Young's modulus $E$ based on (18), the double- $K$ fracture parameters, that is, $K_{\mathrm{Ic}}^{\mathrm{ini}}$ and $K_{\mathrm{Ic}}^{\mathrm{un}}$, and the residual fracture energy $G_{F}$ are summarized in Table 1 .

Figure 8 shows typical complete load-displacement curves for different heating temperatures up to $600^{\circ} \mathrm{C}$. The figure shows that the ultimate load $P_{u}$ decreases significantly with increasing temperatures $T_{m}$, whereas the crack mouth opening displacement (CMOD) increases with $T_{m}$. The initial slope of ascending branches decreases with heating temperatures and the curves become gradually shorter and more extended.

From Table 1, it is found that the initial load $P_{\text {ini }}$, ultimate load $P_{u}$, the residual Young's modulus $E$, and the double$K$ fracture parameters decrease with the increasing temperatures, whereas the $\mathrm{CMOD}_{\text {ini }}, \mathrm{CMOD}_{c}, \mathrm{CTOD}_{c}$, and $a_{c} / h$ increase with $T_{m}$. The $G_{F}$ sustains a hold-increase-decrease tendency with $T_{m}$; the detailed explanation could be found in our previous work [25].

\section{Residual Crack Extension Resistance Curves ( $K_{R}$-Curves) and Stability Criterion}

4.1. Crack Extension Resistance at Various Temperatures. Since the $K_{R}$-curve is considered as a criterion for complete description of crack propagation in structure, it is regarded as the material properties of the complete fracture process. The procedure to calculate the crack extension resistance curves ( $K_{R}$-curves) is programmed using the analytical expressions given in Section 3. The P-CMOD curves shown in Figure 8 are used. The $K_{R}$-curves at different temperatures with crack extension from $65^{\circ} \mathrm{C}$ to $600^{\circ} \mathrm{C}$ are plotted in Figures 9(a) $9(c)$.

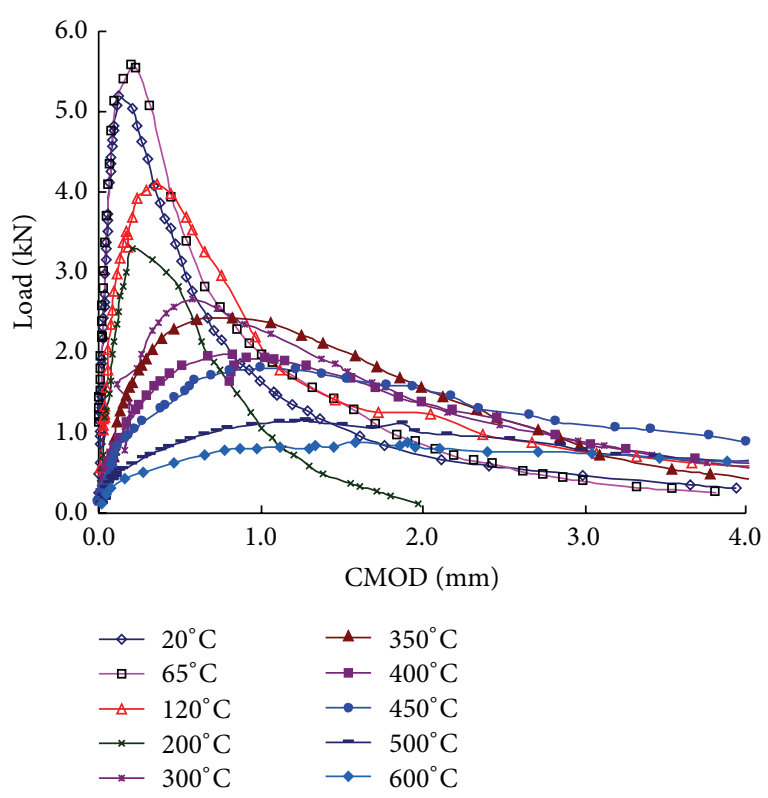

FIGURE 8: Load versus CMOD curves of specimens with temperatures.

When temperatures are less than $200^{\circ} \mathrm{C}$, the $K_{R}$-curves have almost the same $S$-shape, which have a good coincidence with existed literature [5].

4.2. The Influence of Temperatures on Residual $K_{R}$-Curves. Figure 10 plots the $K_{R}$-curves of all temperatures; it is concluded that the $K_{R}$-curves decrease with increasing temperatures. Generally, temperatures under $120^{\circ} \mathrm{C}$ appear not to induce much thermal damage to concrete; the $K_{R}$-curves of $20^{\circ} \mathrm{C}, 65^{\circ} \mathrm{C}$, and $120^{\circ} \mathrm{C}$ are close. Between $200^{\circ} \mathrm{C}$ and $600^{\circ} \mathrm{C}$, higher temperatures cause more damage to the concrete, and the $K_{R}$-curves drop significantly. When temperature reaches $600^{\circ} \mathrm{C}$, the $K_{R}$-curve almost increases linearly with a small margin.

4.3. The Stability Analysis of Crack Propagation. The $K_{R^{-}}$ curve presents the material properties of the complete fracture process. So, the $K_{R}$-curve can be taken as a criterion for describing the crack propagation in a structure or a structural component.

On the contrary, the stress intensity factor curve ( $K$ curve) during the crack propagation in the structure or the structural component must be calculated already. At an arbitrary loading stage on a wedge-splitting specimen, the stress intensity factor at the tip of a propagating crack can be evaluated by inserting the load $P$ and the length of the propagating crack $a$ into formula (21). For the complete fracture process, the stress intensity factor at the tip of the propagating crack caused by the external load $P$ can be plotted as a curve using formula (21).

Herein, the length of the propagating crack is taken as a horizontal axis, and the crack extension resistance $K_{R}(\Delta a)$, the stress intensity factor $K$, and the corresponding load $P$ 


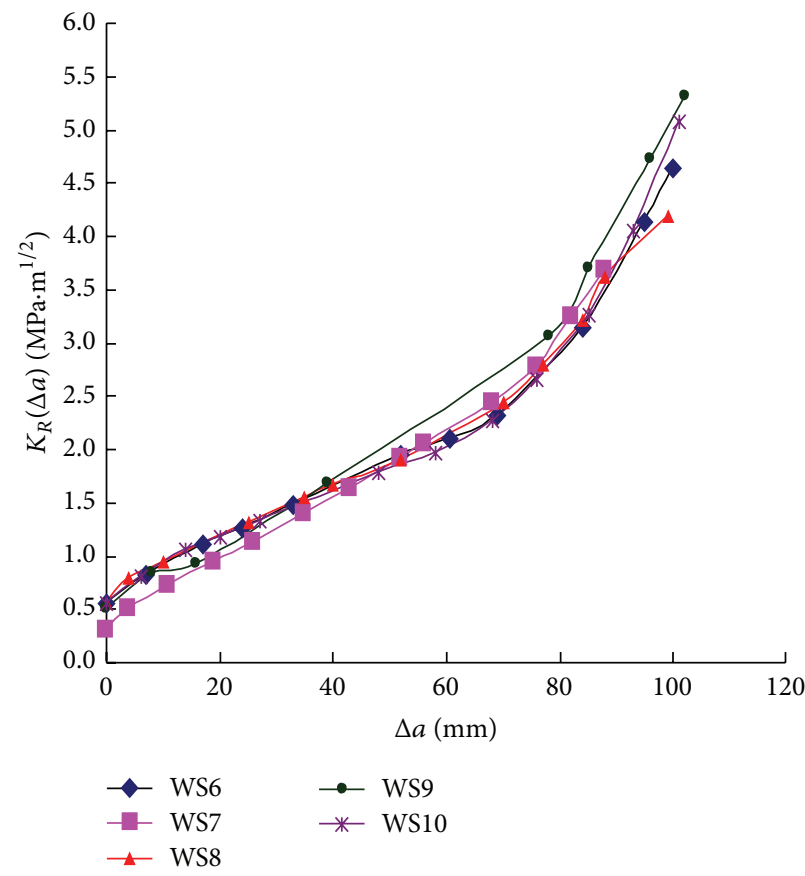

(a) $K_{R}$-curves at $65^{\circ} \mathrm{C}$

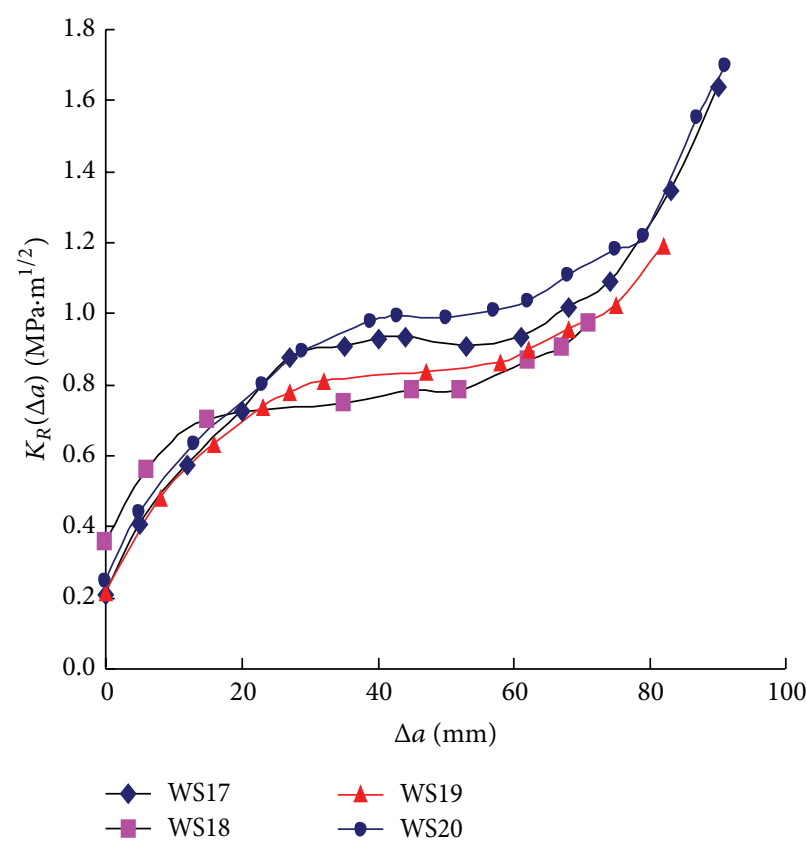

(b) $K_{R}$-curves at $200^{\circ} \mathrm{C}$

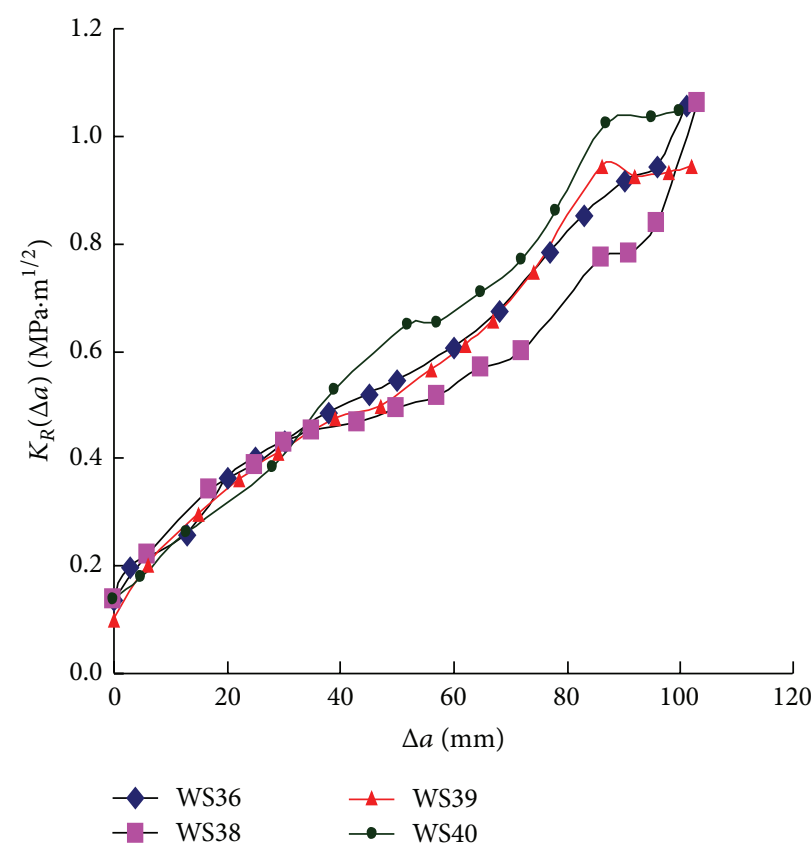

(c) $K_{R}$-curves at $450^{\circ} \mathrm{C}$

FIGURE 9: $K_{R}$-curves with crack extension length of various temperatures.

are plotted on the vertical axis in Figures 11(a) 11(d). From those figures, the stability analysis of the crack propagation during the complete fracture process could be carried out.

From the initial point $B$ to the critically unstable point $C$ during the crack propagation, the toughness of the material increases with increasing crack extension from the inherent toughness $K_{\mathrm{Ic}}^{\mathrm{ini}}$ to the value of the crack extension resistance at the critically unstable point which is denoted by $K_{R}\left(\Delta a_{c}\right)$. The difference between $K_{R}\left(\Delta a_{c}\right)$ and $K_{\mathrm{Ic}}^{\mathrm{ini}}$ is caused by the cohesive force on the fictitious crack zone during the crack propagation.

A common character of Figures $11(\mathrm{a}) \sim 11(\mathrm{~d})$ is that when the maximum load $P_{\max }$ is reached, the stress intensity factor curve ( $K$-curve) coincides with the crack extension resistance 


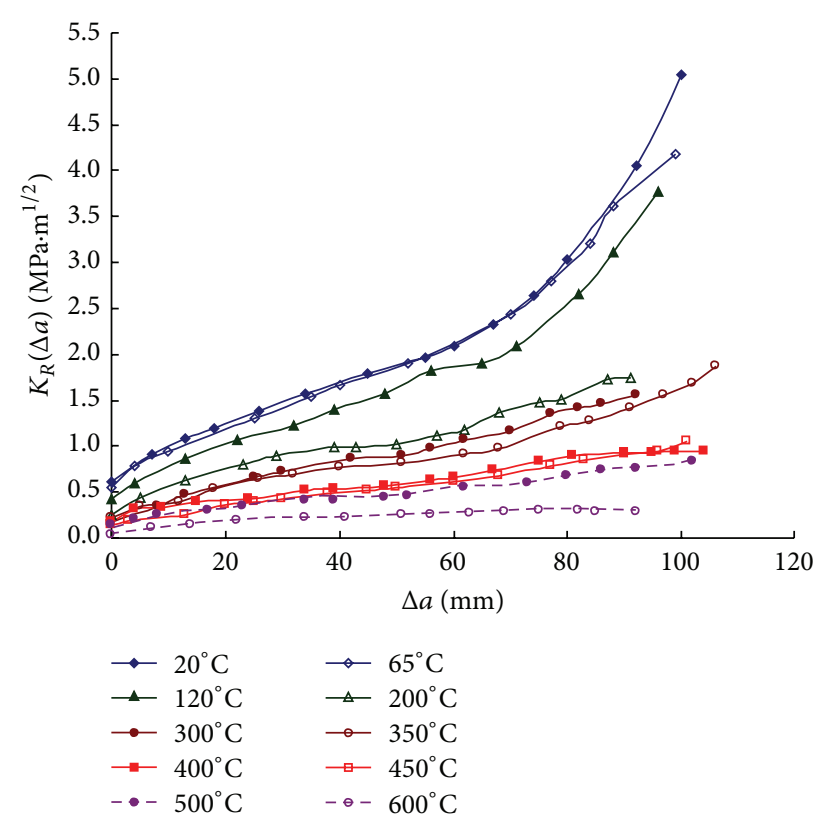

FIGURE 10: $K_{R}$-curves with crack extension length of all temperatures.

curve $\left(K_{R}\right.$-curve) at the point at which the value of the vertical coordinate is equal to the value of the unstable fracture toughness $K_{\mathrm{Ic}}^{\mathrm{un}}$. All of them correspond to the related critical crack length $a_{c}$.

Furthermore, it can be seen that when the curve of the stress intensity factor is lower than the crack extension resistance curve, the crack propagates steadily which can be observed in the region between point $B$ and point $C$. Otherwise, when the $K$-curve coincides with or is higher than the $K_{R}$-curve, the crack propagates unsteadily. The stability analysis can be expressed mathematically as given below:

$$
\begin{gathered}
K_{\mathrm{Ic}}^{\mathrm{ini}}<K(P, a)<K_{\mathrm{Ic}}^{\mathrm{un}} \quad \text { crack propagates steadily, } \\
K(P, a)>K_{\mathrm{Ic}}^{\mathrm{un}} \quad \text { crack propagates unsteadily. }
\end{gathered}
$$

\section{Conclusions}

The residual crack extension resistance $K_{R}(\Delta a)$ associated with cohesive stress distribution in fictitious crack zone is evaluated for wedge-splitting specimens using analytical method. The analytical formulations of the residual $K_{R}(\Delta a)$ for the complete fracture process are presented which consist of two parts. One part is the initiation toughness of the material $K_{\mathrm{Ic}}^{\mathrm{ini}}$, and the other part is an overall value of stress intensity factor $K_{\mathrm{Ic}}^{c}$ caused by the cohesive stress along the fictitious crack zone that increases with the crack extension $\Delta a$. The distributions of the cohesive forces along the fictitious crack zone for varied loading stages are determined according to the softening traction-separation law of the concrete materials.
In the calculation of residual crack extension curves $\left(K_{R^{-}}\right.$ curves) of wedge-splitting specimens subjected to different temperatures, it is found that in each temperature, the fracture toughness $K_{R}(\Delta a)$ increases with increasing crack length $\Delta a$, while the $K_{R}$-curves decrease with increasing temperatures. Generally, temperatures under $120^{\circ} \mathrm{C}$ appear not to induce much thermal damage to concrete; the $K_{R^{-}}$ curves of $20^{\circ} \mathrm{C}, 65^{\circ} \mathrm{C}$, and $120^{\circ} \mathrm{C}$ are close. Between $200^{\circ} \mathrm{C}$ and $600^{\circ} \mathrm{C}$, high temperatures cause more thermal damage to the concrete, and the $K_{R}$-curves drop significantly. When temperature reaches $600^{\circ} \mathrm{C}$, the $K_{R}$-curve increases almost linearly with a small margin.

For the stability analyses of crack propagation, the comparison between $K_{R}$-curves and the corresponding stress intensity factor curves ( $K$-curves) shows that $K_{R}$-curves can be taken as a crack propagation criterion to judge the stability of the crack in the loaded structures; that is, when the stress intensity factor $K(P, a)$ is smaller than the crack extension resistance $K_{R}(\Delta a)$, the crack propagates steadily. Contrarily, when $K(P, a)$ is larger than $K_{R}(\Delta a)$, the crack propagates unsteadily.

\section{Nomenclature}

$a$ : $\quad$ Equivalent-elastic crack length

$a_{c}$ : Critical notch depth of the specimen

$a_{s}$ : $\quad$ Effective crack length corresponding to $w_{s}$

$a_{w 0}$ : $\quad$ Effective crack length corresponding to

CMOD: Crack mouth opening displacement

CTOD: Crack tip opening displacement

E: $\quad$ Residual Young's modulus

$G_{F}: \quad$ Fracture energy: N/m

$h: \quad$ Height of wedge-splitting specimens

$K_{R}: \quad$ Crack extension resistance

$K_{c}(\Delta a)$ : Cohesive toughness

$\sigma(w)$ : Cohesive stress at the tip of initial notch

$\sigma(x)$ : Cohesive stress at equivalent-elastic crack

length $x$

$P_{u}: \quad$ Maximum load

$w_{0}$ : Crack width at stress-free point

$w$ : Crack opening displacement at the tip of

w. initial notch

$a_{0}: \quad$ Initial notch depth of the specimen

$\Delta a: \quad$ Crack extension length

$a_{w c}$ : $\quad$ Fully developed fictitious fracture zone

CMOD: $\begin{aligned} & \text { length } \\ & \text { Critical crack mouth opening }\end{aligned}$

$\mathrm{CMOD}_{c}$ : displacement

$\mathrm{CTOD}_{c}$ : Critical crack tip opening displacement

$f(\sigma)$ : Cohesive force distribution

$f_{t}$ : Tensile strength

$h_{0}$ : Thickness of the clip gauge holder

$K_{\mathrm{Ic}}^{\text {ini }}: \quad$ Initial fracture toughness

$K$ : $\quad$ Stress intensity factor

$\sigma_{s}\left(w_{s}\right)$ : Cohesive stress at the break point of softening curve 


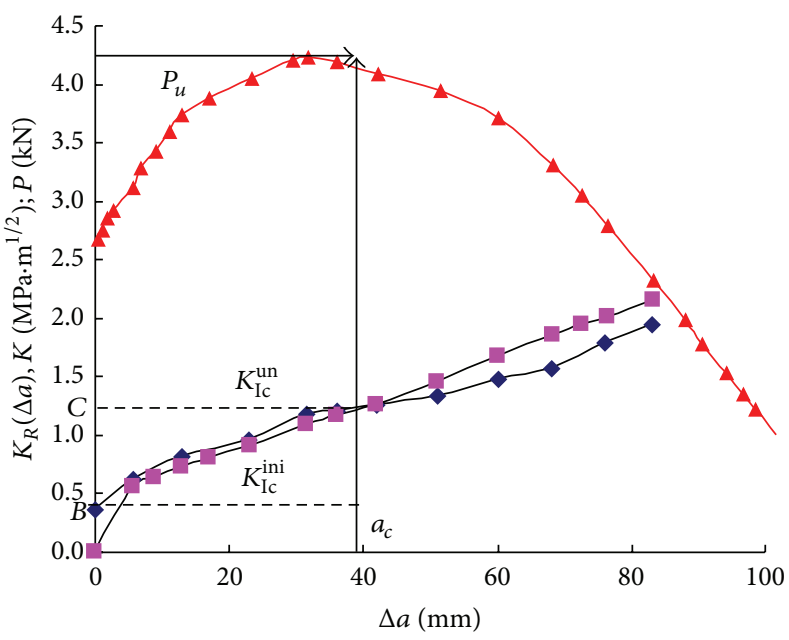

$\neg$ WS4-crack extension resistance

- - WS4-stress intensity factor

$\neg$ Load

(a) Stability analysis of crack propagation at room temperature

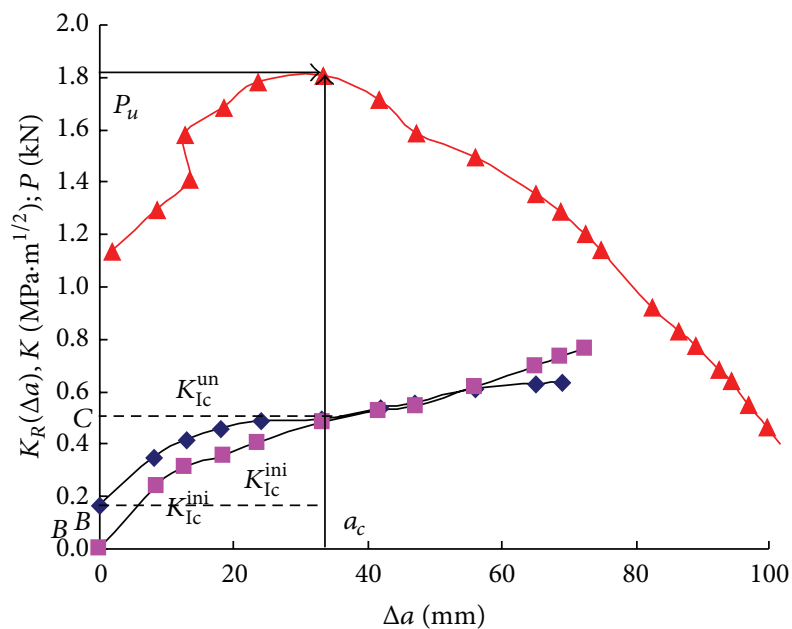

- WS23-crack extension resistance

- - WS23-stress intensity factor

$\rightarrow$ Load

(c) Stability analysis of crack propagation at $300^{\circ} \mathrm{C}$

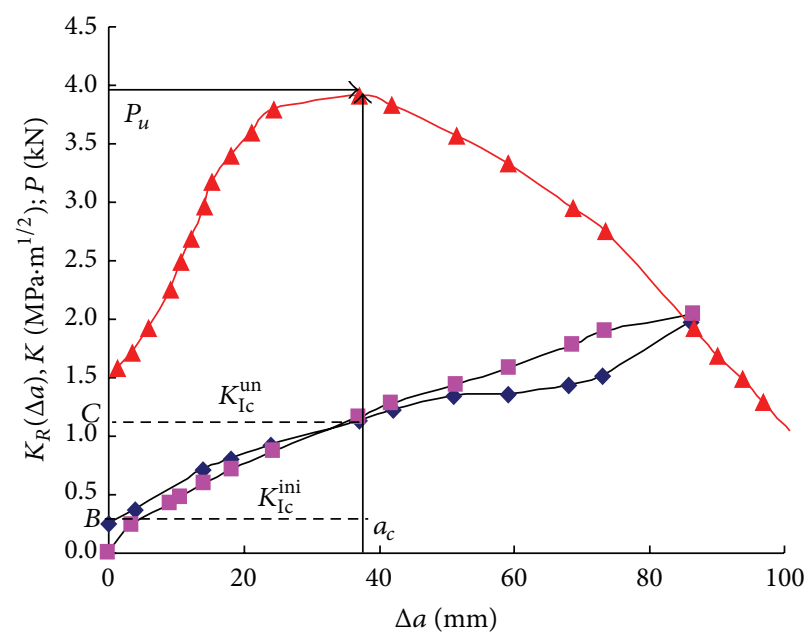

- WS14-crack extension resistance

-n WS14-stress intensity factor

$\rightarrow$ Load

(b) Stability analysis of crack propagation at $120^{\circ} \mathrm{C}$

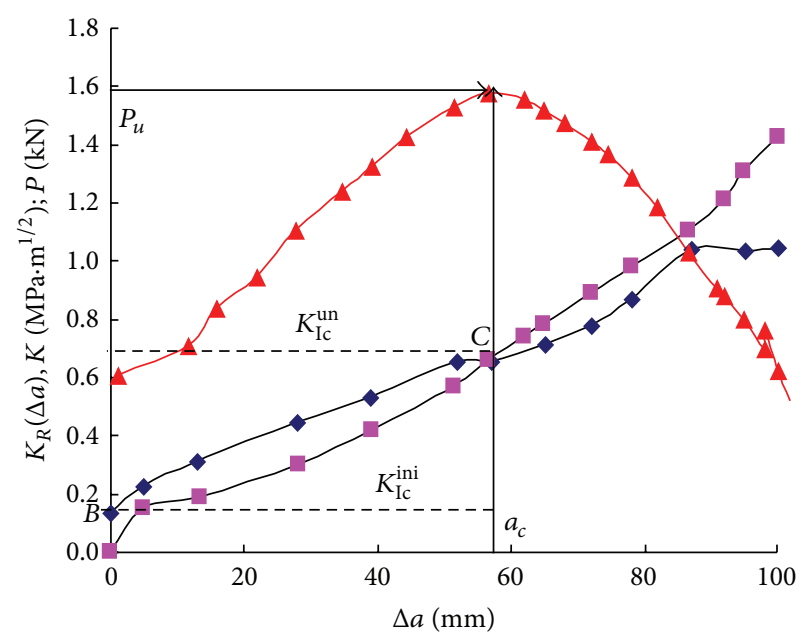

- WS40-crack extension resistance

- WS40-stress intensity factor

$\rightarrow$ Load

(d) Stability analysis of crack propagation at $450^{\circ} \mathrm{C}$

FIGURE 11: Stability analysis of crack propagation of various temperatures.

$P_{\text {ini }}:$ The initial cracking load

$T_{m}$ : Heating temperatures

$w_{s}$ : Crack width at break point of softening curve.

\section{Conflict of Interests}

The authors declare that they have no conflict of interests regarding the publication of this paper.

\section{Acknowledgments}

The State Laboratory of Disaster Reduction in Civil Engineering (SLDRCE09-D-02) and the Young Scientist Project of Natural Science Foundation of China (NSFC: 51008235) have supported this research.

\section{References}

[1] H. K. Hilsdorf and W. Brameshuber, "Size effects in the experimental determination of fracture mechanics parameters," in 
Application of Fracture Mechanics to Cementitious Composites, S. P. Shah, Ed., pp. 361-397, NATO-ARW, 1984.

[2] Y. W. Mai, "Fracture measurements of cementitious composites," in Application of Fracture Mechanics to Cementitious Composites., S. P. Shah, Ed., pp. 399-429, NATO-ARW, 1984.

[3] B. L. Karihaloo and S. P. Shah, "Do plain and fiber-reinforced concretes have an R-curve behavior?" in Fractures of Concrete and Rock, S. P. Shah and S. E. Swartz, Eds., pp. 96-105, Springer, New York, NY, USA, 1987.

[4] S. Xu and H. W. Reinhardt, "Determination of double- $K$ criterion for crack propagation in quasi-brittle fracture, part I: experimental investigation of crack propagation," International Journal of Fracture, vol. 98, no. 2, pp. 111-149, 1999.

[5] S. Xu and H. W. Reinhardt, "Crack extension resistance and fracture properties of quasi-brittle softening materials like concrete based on the complete process of fracture," International Journal of Fracture, vol. 92, no. 1, pp. 71-99, 1998.

[6] S. Xu and H. W. Reinhardt, "Determination of double-K criterion for crack propagation in quasi-brittle fracture, part II: analytical evaluating and practical measuring methods for three-point bending notched beams," International Journal of Fracture, vol. 98, no. 2, pp. 151-177, 1999.

[7] Comite Euro-International du Beton (CEB), CEB-FIP Model Code Bulletin D' Information, EPF Lausanne, 1990.

[8] H. W. Reinhardt, H. A. W. Cornelissen, and D. A. Hordijk, "Tensile tests and failure analysis of concrete," Journal of Structural Engineering, vol. 112, no. 11, pp. 2462-2477, 1986.

[9] S. Kumar and S. V. Barai, "Influence of specimen geometry and size-effect on the $\mathrm{K}_{R}$-curve based on the cohesive stress in concrete," International Journal of Fracture, vol. 152, no. 2, pp. 127-148, 2008.

[10] Z. P. Bazand, P. Bazant, and P. C. Prat, "Effect of temperatures and humidity on fracture energy of concrete," ACI Materials Journal, vol. 85, no. 4, pp. 262-271, 1988.

[11] G. Baker, "The effect of exposure to elevated temperatures on the fracture energy of plain concrete," Materials and Structures, vol. 29, no. 190, pp. 383-388, 1996.

[12] B. Zhang, N. Bicanic, C. J. Pearce, and G. Balabanic, "Residual fracture properties of normal- and high-strength concrete subject to elevated temperatures," Magazine of Concrete Research, vol. 52, no. 2, pp. 123-136, 2000.

[13] C. V. Nielsen and N. Bićanić, "Residual fracture energy of highperformance and normal concrete subject to high temperatures," Materials and Structures, vol. 36, no. 262, pp. 515-521, 2003.

[14] B. Zhang and N. Bicanic, "Fracture energy of high-performance concrete at high temperatures up to $450^{\circ} \mathrm{C}$ : the effects of heating temperatures and testing conditions (hot and cold)," Magazine of Concrete Research, vol. 58, no. 5, pp. 277-288, 2006.

[15] G. Prokopski, "Fracture toughness of concretes at high temperature," Journal of Materials Science, vol. 30, no. 6, pp. 1609-1612, 1995.

[16] H. Abdel-Fattah and S. A. Hamoush, "Variation of the fracture toughness of concrete with temperature," Construction and Building Materials, vol. 11, no. 2, pp. 105-108, 1997.

[17] P. E. Petersson, "Crack growth and development of fracture zones in plain concrete and similar materials," Report TVBM1006, Division of Building Materials, Lund Institute of Technology, Lund, Sweden, 1981.

[18] V. S. Gopalaratnam and S. P. Shah, "Softening response of plain concrete in direct tension," Journal of the American Concrete Institute, vol. 82, no. 3, pp. 310-323, 1985.
[19] H. K. Hilsdorf and W. Brameshuber, "Code-type formulation of fracture mechanics concepts for concrete," International Journal of Fracture, vol. 51, no. 1, pp. 61-72, 1991.

[20] D. V. Phillips and Z. Zhang, "Direct tension tests on notched and un-notched plain concrete specimens," Magazine of Concrete Research, vol. 45, no. 162, pp. 25-35, 1993.

[21] A. Hillerborg, M. Modéer, and P.-E. Petersson, "Analysis of crack formation and crack growth in concrete by means of fracture mechanics and finite elements," Cement and Concrete Research, vol. 6, no. 6, pp. 773-781, 1976.

[22] H. Tada, P. C. Paris, and G. Irwin, The Stress Analysis of Cracks Handbook, Paris Productions Incorporated, St. Louis, Mo, USA, 1985.

[23] Y. S. Jenq and S. P. Shah, "Two parameter fracture model for concrete," Journal of Engineering Mechanics, vol. 111, no. 10, pp. 1227-1241, 1985.

[24] S. $\mathrm{Xu}$ and H. W. Reinhardt, "Determination of double- $K$ criterion for crack propagation in quasi-brittle fracture, Part III: compact tension specimens and wedge splitting specimens," International Journal of Fracture, vol. 98, no. 2, pp. 179-193, 1999.

[25] J. Yu, K. Yu, and Z. Lu, "Residual fracture properties of concrete subjected to elevated temperatures," Materials and Structures, vol. 45 , no. 8, pp. 1155-1165, 2012. 

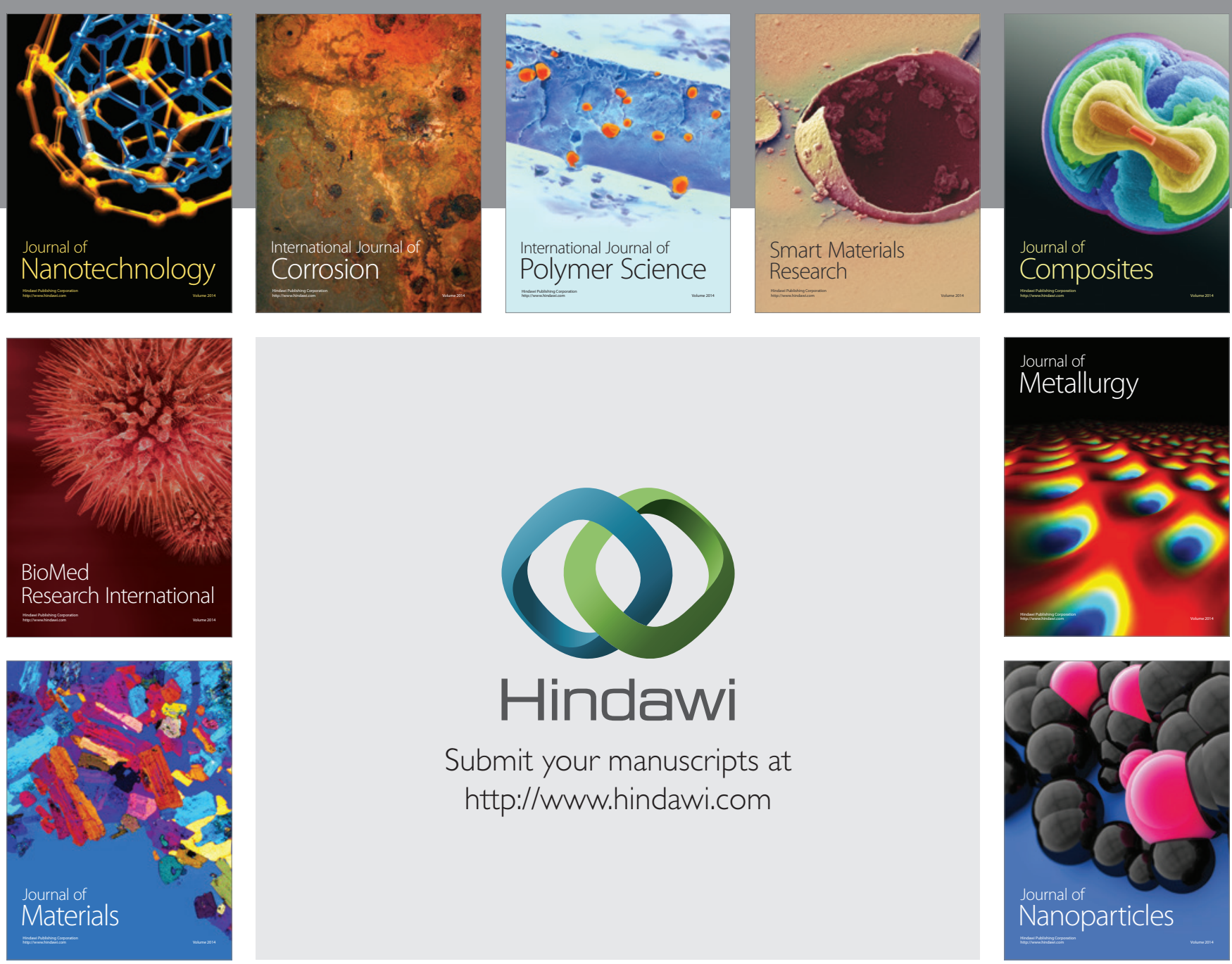

Submit your manuscripts at http://www.hindawi.com
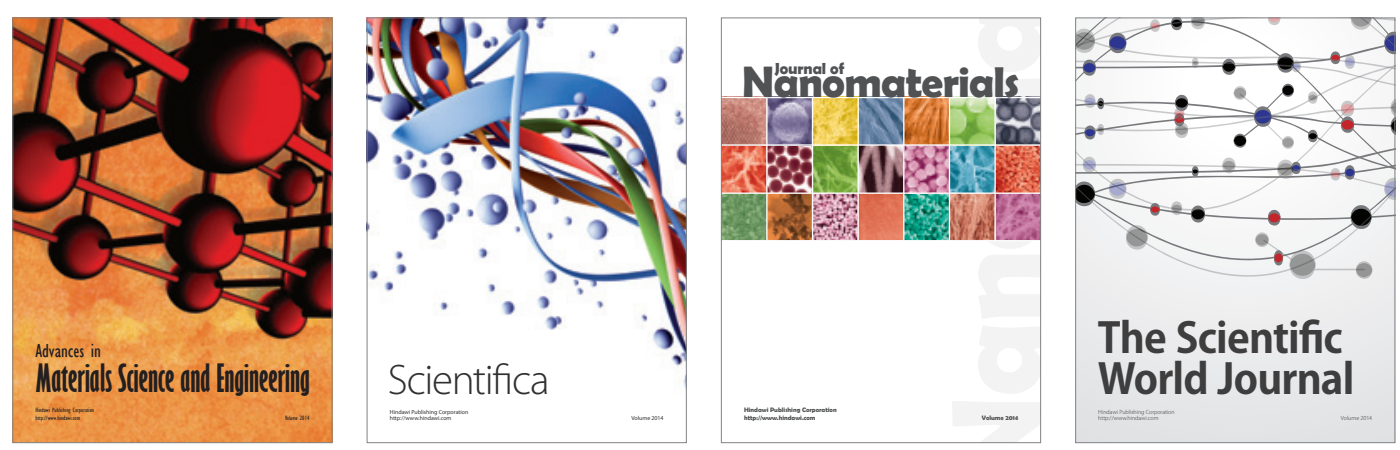

\section{The Scientific World Journal}
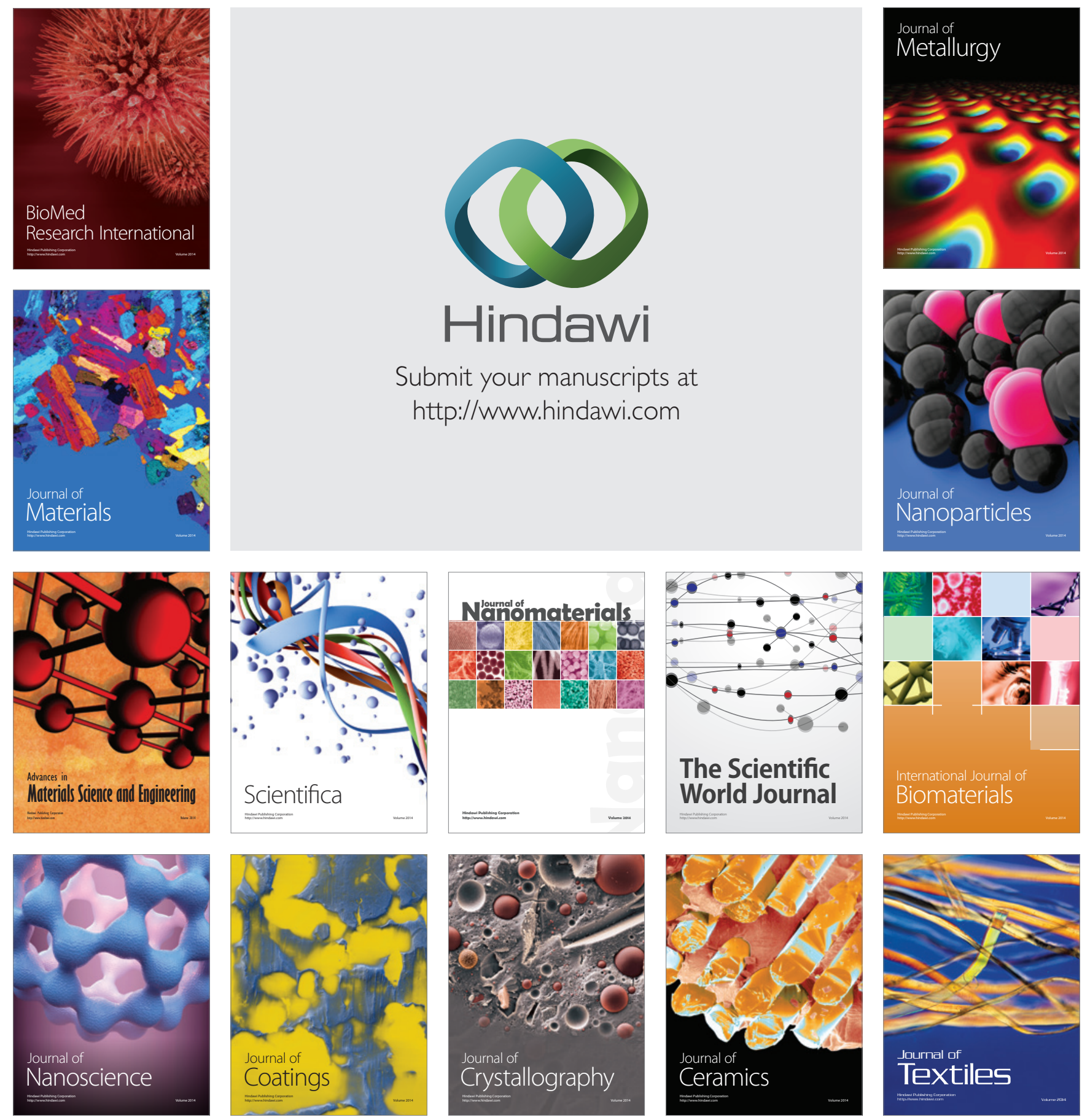